\title{
Whether Codeswitching can Project Identity? -Relationship between Codeswitching and Identity among Malaysian Chinese University Students
}

\author{
Yong Wu \\ English Faculty, Zhejiang Yuexiu University, Shaoxing, China \\ Email: 704991373@qq.com
}

How to cite this paper: $\mathrm{Wu}, \mathrm{Y}$. (2021). Whether Codeswitching can Project Identity?-Relationship between Codeswitching and Identity among Malaysian Chinese University Students. Advances in Literary Study, 9, 91-103.

https://doi.org/10.4236/als.2021.92011

Received: April 2, 2021

Accepted: April 24, 2021

Published: April 27, 2021

Copyright ( 2021 by author(s) and Scientific Research Publishing Inc. This work is licensed under the Creative Commons Attribution International License (CC BY 4.0).

http://creativecommons.org/licenses/by/4.0/

\begin{abstract}
The current study was designed to understand the relationship between identity and codeswitching among 240 Malaysian Chinese undergraduate students. The data for this study consisted of questionnaires, interview samples, and various observational records. The results reveal that there is a significant relationship between identity and codeswitching. This research also indicated how Malaysian Chinese students use codeswitching when communicating with people through observational note-taking, audiotaping, and videotaping.
\end{abstract}

\section{Keywords}

Identity, Codeswitching, Malaysian Chinese, Undergraduate Students, Language

\section{Introduction}

With the influence of internationalization and globalization, the phenomenon of multilingualism is increasing. In many countries in Southeast Asia, bilingualism's popularity is increasing due to historical and political reasons. Malaysia is the place where the monsoons meet, and it is also the historical intersection of the two major civilizations in Asia (China, India) and Western civilization. Malay, English, Chinese, and Tamil are all derived from different language families and cultural traditions, and they all come together in the end. The multilingual social environment is a prerequisite for the existence of code-switching.

Malaysian Chinese have long lived in a multilingual society. During the British colonial rule, Malaysian Chinese mainly communicated in English, Chinese and Chinese dialects. After long-term and stable contact with Chinese, the phe- 
nomenon of mutual interference and borrowing with many other languages occurred, especially in terms of vocabulary borrowing. After a long time of accumulation and precipitation, both Malaysian Chinese and English have absorbed other language systems' components, causing the original language structure to mutate. With several languages and dialects at their disposal, Malaysian Chinese speakers are bilinguals or trilingual and are expected to speak in standard Chinese, Bahasa Melayu, and English. In Malaysia today, it is not feasible and impossible to use only one language for a long time. There are so many different kinds of languages in Malaysia, which are used in society without restriction. It is a natural law to influence each other. The Chinese are facing a multilingual environment. Broadcasting, newspapers, and other media and interpersonal communication in various languages affect Malaysian Chinese's language all the time. In a few minutes of conversation, the local Chinese can use several languages one after another, without any pause in thinking about transcoding, and the code conversion may be words, phrases, or entire sentences.

Hence, code-switching is seen as a common everyday language situation where speakers change from one language to another. Meanwhile, code-switching has become an integral part of the speakers' speech style as they code-switch within a single utterance, and it has appeared to be a new language variety (Lim, 1997; David, 2003; David, 2009; Morais, 1991; Le Vasan, 1996; Jamaliah, 1995).

Although some scholars have studied the phenomenon of codeswitching in Malaysia from different perspectives, such as from the perspectives of language history, language policy, word variation, national education, education, and the status quo of Chinese in Malaysia, there are not many types of research on the interrelationship between choice and linguistic identity. The code-switching of Malaysian Chinese in interacting with their own and other ethnic groups involves language users and social issues such as their psychology, physiology, and identity construction. Therefore, from the perspective of pragmatics, it is of particular significance to study the new generation of Malaysian Chinese youth's code-switching in their interactions with their nation and other nations to form the identity construction.

\section{Literature Review}

\subsection{Code-Switching}

Code-switching drew quite a little attention from only a few scholars in the field of linguistics when the phenomenon first appeared in the 1920s. Code-switching is a typical phenomenon in a multiracial and multilingual country such as Malaysia. Crystal (1987), Berthold, Mangubhai, and Bartorowicz (1997) suggested that code-switching is the bilinguals' ability to effortlessly alternate between two languages during a single speech or their conversations. Code-switching is considered a type of alteration of diverse forms, including sentences and phrases alteration from two languages (Skiba, 1997). Other studies found that codeswitching is affected by several sociolinguistic factors in which "can be done by 
simply borrowing some lexical items from another language or by switching from one language to another" (Dumanig, 2010: p. 40).

Based on previous studies, code-switching takes place in a variety of domains. For example, in Malaysia, code-switching happens in the home domain regardless of their family's background (Jariah, 2006: David, 2001; Kuang, 2002). When referring to food items, it may happen, accommodating one's lack of proficiency, indicating solidarity, rapport, distancing, teasing, aggravation, and reprimanding (David, 2009). Additionally, code-switching is also practiced by professional's informal situations. Here, it is used to explain ambiguous statements in communication. Tan (1993) discovers that ESL teachers in Malaysia had made meaningful code-switching patterns from English to Bahasa Melayu during classes. The switches were not done at random, but they occurred when the previous language was not effective.

Hong (2007) studied Malaysian social changes and local Chinese language transfer from Malaysian Chinese's perspective. This research explores the three generations of the same family in Malaysia from the macro sociolinguistic perspective, exploring history background, education, and social factors that influenced the Malaysian Chinese codeswitching. An in-depth investigation shows when a speaker switches from English to Bahasa Melayu or Chinese as a conscious group identification act, and code-switching is used as an identity marker in Malaysia. Hamers and Blanc (2000: p. 266) also indicated that code-switching is used as a communicative strategy and a marker of ethnic-group membership and identity. Speakers make use of code-switching when they want to signal the membership of a particular group identity.

Many studies have examined the factors and the different code-switching patterns (Dumanig, 2010). The regularities in alternating between languages in a particular speech community are also associated with specific social roles. These are considered as rights and obligations (Myers-Scotton, 1993; Dumanig, 2010). Myers-Scotton (1993) further explained that a participant indicates her understanding of the relevant role in the current situation and context when speaking a particular language. Speakers must share an understanding of the social meanings and significance of particular language choices as a basis. Besides its use of filling linguistic gaps and achieves discursive aims, code-switching is often practiced to show group identification or speakers' identity of several ethnic groups (Morais, 1991).

\subsection{Identity}

According to Fishman (1999), identity means "who you are," which is your distinctiveness of being a particular person. In the social sciences, identity is how individuals mark themselves as parts of a social group. In psychology, it refers to a person's confidence or self-image.

Scholars like Bucholtz and Hall (2003; 2004a; 2004b) perceive identity as a developing concept based on different situations. They defined identity as "the 
self and others" ( $p$ 586). Here, the notion of others in identity construction is recognized. Identity is seen as a sort of fluid characteristic of changing, actively constructed, and co-constructed while receiving acknowledgment from others through interaction. It is continually built and perceived through someone's involvement in individual, social, and institutional activities. Mckinley, Mastro, and Warber (2014) clarified that "language is inevitably at the center stage of identity construction in multilingual and multidialectal contexts where language choices have to be made" (p. 221).

Further explained by Paltridge (2006), one's identity can be observed through the use of language, multi-modal activities, and communities in which one is in it. His research allows someone to have multi identities with roles assigned. Hence, a person may be displayed as many characters or identities according to the settings (Gee, 2005; Thornborrow, 1999; Widyawati, 2015; Cameron, 2001). These descriptions of identity help to conclude that identity is subjective and not static. It is constructed and developed through various social situations and contexts.

In Social Identity Theory, the phenomenon of using language to portray different personal identities through social groups is considered a natural occurrence. The social group refers to individuals who assume themselves as members of the same social category with mutual social identity. People tend to categorize themselves into many social categories, such as religious affiliation, organizational membership, gender, etc. This social classification enables one to define oneself in the social setting (Tajfel \& Turner, 1985). The in-group and out-groups existence would lead to social behaviors such as prejudiced or discriminatory attitudes against certain social groups within a community due to bias and favoritism within the in-group.

The role of language in this process comes when language is used as a potent symbol of identity to test or maintain intergroup boundaries (Meyerhoff, 2006). Stets and Burke (2000) added that persons are labeled as the in-group and the out-group through social comparison in the social category. The in-group is for persons similar to the self, whereas the out-group differs from the self. Thus, one may use different languages when communicating with the in-group and the out-group to balance the affiliation and the differences between oneself and the other person when people try to include themselves in a particular social group using the language interlocutors know. It fosters a sense of self-belonging to those with solid dialect attachment or a sense of self-identity.

Moreover, David (2006) studied this view based on social identity theory, where he investigated language shifting in a Hong Kong Chiuchao family. The findings discovered that the Chiuchao immigrants identify themselves as Hong Kong people rather than Chiuchaonese. Here, it suggests that the shift of language indicates the shift of self-identity. Mckinley, Mastro, and Warber (2014) examined two groups of Latino (in-group) and white customers (out-group) exposed to positive Latino media exemplars. The results find that one's race or 
ethnicity may promote in-group favoring responses, and for the out-group members, in-group racial/ethnic identification is an essential factor, especially in media-related interethnic evaluations.

\subsection{Identity and Codeswitching}

Various studies have been done in language and identity, covering a wide range of contexts and social categories such as gender, race, and nation. Omar (1993) also studied the relationship between language and ethnicity. It was concluded that the common language acts as a marker of cultural identity-linguistic identity changes with the environment, language use, and development of the individual.

Jariah (2003) also pointed out that learning a language involves internalizing cultural features, which are the linguistic system's significant characteristics. "The language spoken by somebody and his or her identity as a speaker of this language are inseparable" (Tabouret-Keller, 1997: p. 315). In addition to recognizing the vital link between language and Identity, Tabouret-Keller reminded us that identity is endlessly created according to social constraints, social interactions, and wishes that may be subjective and unique (p. 316).

According to Gumperz (1982), bilinguals choose one or the other language to index the codeswitching identities. However, Hong (2010) indicated that: code-switching is very common, especially among the younger generation, by using questionnaires and interviews with three different generations (grandparents, children, and grandchildren) in Malaysia Chinese families. She also emphasized that in a pluralistic society, young Malaysian Chinese have a relatively high level of education and solid trilingual skills, but they have their own language choice (English) and tend to move closer to the Malay culture to express them.

When faced with Western and local culture's impact, it is impossible to preserve their ancestors' traditional Chinese culture forever. In order to survive, Malaysian Chinese must integrate into the local mainstream society. Therefore, the integration results are expressed in the language and formed a special relationship among Malaysian Chinese. However, in light of recent nonessentialist conceptualizations of identity, this straightforward association of language and identity is still open to questioning.

The research examines the relationship between code-switching and Identity among Malaysian Chinese university students from Kuala Lumpur. The main questions of this study are:

1) What is the relationship between identity and codeswitching among Malaysian Chinese university students?

2) How do Malaysian Chinese students use codeswitching when communicating with people?

3) What attitudes do Malaysian Chinese students use codeswitching when communicating with the people? 


\section{Methodology}

\subsection{Research Design}

The present study is a non-experimental study to examine the relationship between code-switching and identity. The researcher is also interested in exploring the attitudes towards using codeswitching and their identities in a particular social context. This study uses multiple methodologies of questionnaires and interviews to examine the research questions.

\subsection{Participants}

There are 240 Malaysian Chinese undergraduate students from 5 universities: the University of Malaya, National University of Malaysia, University Kuala Lumpur; Taylor University; Help University in the Kuala Lumpur area. Furthermore, five undergraduate students involved in the observation and interviews are all from the University of Malaya but with different faculties. There are two females and three males with an average age are around $20-22$.

\subsection{Data Collecting}

Questionnaires were used as a tool to investigate the first research question. Two hundred forty copies of questionnaires were distributed in 5 universities in the Kuala Lumpur area. Before filling out the questionnaire, explain to the participants the purpose of the research, research questions, research significance, etc. The researcher's personal information will be kept confidential.

Five students' language samples were collected from each subject in school settings to get sufficient bilingual speech data. Due the time allotted for their classroom instructions, the classroom observations were conducted over two months. The data for this research consists of videotapes, audiotapes, and observational notes recorded.

\section{Results and Discussion}

\section{Question 1: What is the relationship between identity and codeswitching} among Malaysian Chinese university students?

According to Figure 1, the primary language used in university and social network domains is diverse. The Malaysian Chinese participants use English when speaking in both university and social network domains. Almost half of the Malaysian Chinese undergraduate students stated that they use primarily English in the university domain, and another 52\% use standard Chinese. However, in the frequency of language use (see Figure 1), the result shows that the usage of standard Chinese by the participants is slightly higher than English in most language situations.

According to Figure 2, codeswitching (standard Chinese and English) is more frequent in Chinese community communication. This code-switching is also used in the social network domain. In the social networking sites such as Facebook, 
e-mail, Forums, and others, the participants may feel like when it comes to using these English or Chinese websites, codeswitching (English and Chinese) could be recognized as the primary communication way.

In contrast, the participants use English-Bahasa Melayu codeswitching predominantly in the university with their lecturers and classmates of different states and races. They use this codeswitching when discussing various university domain issues, including talking about studies, personal and friendship matters. All of these, they want to express their Malaysian citizens.

The use of code-switching in all the domains also proves that mixing codes with different addressees is a typical pattern among Malaysian Chinese. From the findings (see Table 1), it is shown that there is a significant relationship between codeswitching using and their identity.

The data conform to the finding from Lim (1997), where he revealed the

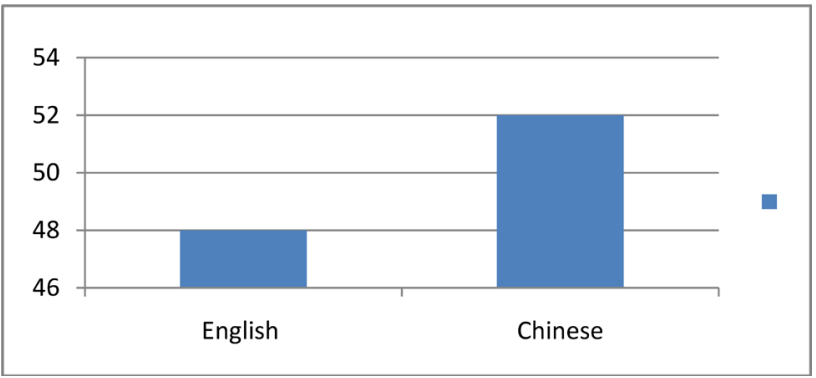

Figure 1. The frequency of language use.

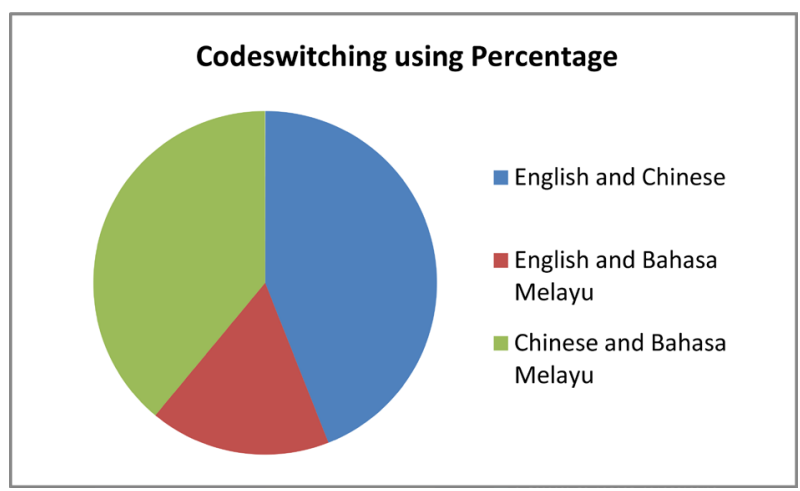

Figure 2. The codeswitching using.

Table 1. Correlation test of codeswitching using and identity.

\begin{tabular}{cccc}
\hline & & codeswitching using & identity \\
\hline \multirow{2}{*}{ codeswitching using } & Pearson Relevance & 1 & $0.619^{* *}$ \\
& Significance. (two-tails) & & 0.000 \\
& Number & 240 & 240 \\
\hline \multirow{2}{*}{ identity } & Pearson Relevance & $0.619^{* *}$ & 1 \\
& significance(two-tails) & 0.000 & 240 \\
\hline
\end{tabular}


popularity of code-switching amongst Malaysian adolescents. Dumanig (2010) also found that code-switching was evidently used among Filipino-Malaysian couples. However, this research is inconsistent with Hong (2007). Only about half of the participants did code-switching, especially in the home and social network domains. Identity is endlessly created according to social constraints, social interactions, and wishes that may be subjective and unique. Within the home and internal social network, using standard Chinese could strongly express their Chinese identity. Malaysian Chinese who have a high degree of recognition of the local culture have more highly regarded English, Malay or alternative languages as their primary life language, while those Malaysian Chinese who actively support the Chinese culture use standard Chinese.

Question 2: How do Malaysian Chinese students use codeswitching when communicating with people?

Code-switching is practiced to accommodate others, to connect linguistic differences, to reduce social distance, to create effective communication, to show affiliation, to establish rapport, or even to withhold information (Jamaliah, 1995; Omar, 1993; Le Vasan, 1996; Morais, 1991; Jariah, 2006; David, 2006; David, 2003; Kow, 2003). The participants' codeswitching in the domains relies on the interlocutor (who), the topic (what), language repertoire, and proficiency. 78\% of them agree that the language which they use most in all domains depends on 'who' they are speaking with and 'what' they are talking about.

One hundred and fifty-one cases of codeswitching occurred among the five Malaysian Chinese undergraduate students, about $15 \%$ of the total of nine hundred and eighty-seven utterances. The number and percentage of codeswitched utterances of the subjects are shown in Table 2, reflecting that unbalanced bilingual subject's codeswitched more frequently than their balanced bilingual counterparts in the classroom setting, an average frequency of $32.5 \%$ versus $8.9 \%$. This result is due to their interaction pattern. The balanced bilingual students interacted with the monolingual English speakers dominantly, while the unbalanced bilingual students interacted with the other bilingual students and Chinese-dominant speakers.

Table 3 shows the distribution of codeswitching employed by five Malaysian Chinese in the classroom setting. Syntactically, Chinese bilingual subjects switched intersententially more frequently than intrasententially, $66.9 \%$ versus $33.1 \%$. Language competence of the subjects did not significantly influence

Table 2. The proportion of codeswitching utterance at school.

\begin{tabular}{cccccc}
\hline codeswitching & JM & SW & CH & CA & AJ \\
\hline N & 6 & 17 & 12 & 54 & 33 \\
$\mathrm{~T}$ & 115 & 186 & 72 & 293 & 131 \\
$\%$ & 5.2 & 9.1 & 16.7 & 18.4 & 25.2 \\
\hline
\end{tabular}

Note: $\mathrm{N}$ indicated the frequency of codeswitching; $\mathrm{T}$ indicated the number of total utterances; \% indicates the proportion of codeswitching in the total utterance 
Table 3. Distribution of Codeswitching at school.

\begin{tabular}{ccccccc}
\hline & \multicolumn{2}{c}{ situational } & \multicolumn{2}{c}{ stylistic } & \multicolumn{2}{c}{ total } \\
\cline { 2 - 7 } & $\mathrm{N}$ & $\%$ & $\mathrm{~N}$ & $\%$ & $\mathrm{~N}$ & $\%$ \\
\hline intersentential & 70 & 46.4 & 31 & 20.5 & 101 & 66.9 \\
intrasentential & 41 & 27.2 & 9 & 6.0 & 50 & 33.1 \\
Total & 111 & 73.5 & 40 & 26.5 & 151 & 100.0 \\
\hline
\end{tabular}

codeswitching behaviors in terms of syntactic categories and the language structure in which codeswitching occurred. However, balanced bilingual subjects showed a slightly higher frequency of intrasentential codeswitching than unbalanced bilingual subjects, with an average frequency of $43 \%$ versus $35.8 \%$. Sociolinguistically, situational codeswitching occurred more frequently than stylistic ones, $73.5 \%$ versus $26.5 \%$, as indicated by Table 3 . This result was true of all the subjects, regardless of their language competence.

The findings are confirmed with the findings from Paltridge (2006)'s study. The learners' social contacts in this domain are also varied with different backgrounds, ethnicities, religions, and languages. Identity with a particular culture often determines his language attitude, and the language that can be shared in the community is the basis for establishing a sense of cultural identity. A person's cultural identity, language attitude, and language use codeswitching often influence each other and have the characteristics of having "You" in "I" and "I" in "You".

Question 3: What attitudes do Malaysian Chinese students use codeswitching when communicating with people?

1) Attitudes towards using Codeswitching

According to the interview, five participants all support that codeswitching has a significant effect on identity construction. Codeswitching can be considered a dominant language phenomenon for them as it is used in the two domains of university and social network. They all recognized that they use codeswitching spontaneously without requiring them to make such a choice.

It is also shown that even they are good English speakers, they are still loyal to their heritage and will use standard Chinese or the local dialects whenever it is appropriate. Under this situation, codeswitching (English and Chinese) is easier to happen. In a way, we can conclude that their identities are context-dependent. The participants are also aware that using English is pragmatic since English is valued socially and academically. They also acknowledge the importance of Chinese and the advantages gained for being fluent in English. For example,

"A bonus! You can call yourself a polyglot! I am very proud of people who can speak more than one language. I have a lot of Chinese friends who speak English and Chinese well." "It is a bonus when you can master Chinese and English. I do not find it a problem or a surprise when a Malaysian Chinese can use a code-switching." "When we have dialect or Chinese, 
sometimes it's tough to converse in English. By being able to speak it fluently, it shows that we have the effort to improve our skills". "People are quite impressed, I think. Since I can speak good English and Chinese, I think I prove them wrong, and I'm kind of proud of it". "I think it's nothing new; a lot of people are like this nowadays. But I still think it's a good thing because it means that you can keep up with the modern world by speaking good English and Chinese but still embrace your heritage."

This finding is supported by Omar (1993), which describes in her study that when speakers speak Chinese or English, they have different identity features. Codeswitching is also an efficient way to project a national and ethnic image when using national and ethnic language mixed with projecting a different identity. Although English has become as crucial as their native language in Malaysia, English's impact on Malaysia's Chinese Identity is not permanent and significant. Instead, identity adapts due to many factors, as discussed previously. Ultimately, the participants still consider themselves Malaysian Chinese, and their heritage is always valued. It also shows that codeswitching can be adopted regardless of one's background.

\section{2) Attitudes towards their Malaysia Chinese Identity}

Based on the participants' interviews, it is clear that these people develop a content sense of attachment or pride toward their identity. For example:

"I am proud to be Malaysian Chinese because I have my own unique identity.", "I am proud of it (being Malaysian Chinese) because we are friendly." "Being a Malaysian Chinese is something that builds who I am," "I was born here/Malaysia) and I am proud of where I come from". Since their first languages are either local dialect or standard Chinese, their identity is nurtured by their background and linguistic behavior. In return, it gives an impact on their choice of language based on the identity they are displaying."

There is a sense of pride in preserving their heritage. Malaysian Chinese feel proud of where they come from and whenever they speak the local dialect. This feeling fosters a strong sense of identity within them due to a resilient affection towards their heritage, especially the national language and the dialect. According to the participants, they feel that being Malaysian Chinese and speak good English and Chinese at the same time is something positive and beneficial. Being competent both in English and Chinese makes them feel proud and gives them a rewarding feeling. It also boosts their confidence and self-esteem.

\section{Implications}

The findings in this study also have some educational implications. Firstly, Chinese language teachers should create an environment to accommodate and promote first languages in a classroom setting. Bilingual educators should encourage using the students' first language or codeswitching as an effective coop- 
erative learning strategy and a communicative strategy essential for learning. Secondly, school administrators should provide flexible classroom arrangements for second language learners to provide opportunities for exchanging ideas, peer interactions, and cultural backgrounds and values. Thirdly, Chinese language teachers should use a more effective means of assessing and evaluating language proficiency to incorporate a more holistic way of assessing language development. The students' proficiency should not be measured simply on a numerical scale because of factors that influence usages, such as students' attitudes towards themselves, their families, and their two languages. The possibility exists of assessing language proficiency accurately by observing students in other environments, such as in school and home settings (Commins, 1989). Fourthly, language and culture need to be integrated into the curriculum to educate second language learners to cultivate academically successful bilingual and bicultural learners. Lastly, as social guidance, schools and media must strictly abide by grammatical norms and establish a correct language model. Young people who are establishing a primary language must also learn a standardized language to avoid language confusion. In a society with a complicated humanistic background, one can adopt a more tolerant attitude toward language use and not deliberately prevent language integration. From the perspective of social integration and the recognition of local culture by overseas Chinese, the language mosaic phenomenon has its positive side and is a new page in overseas Chinese development history.

\section{Conclusion}

The current study was designed to understand the relationship between identity and codeswitching among 240 Malaysian Chinese undergraduate students. The data for this study consisted of questionnaires, interview samples, and various observational records. The results reveal that there is a significant relationship between identity and codeswitching. This research also indicated how Malaysian Chinese students use codeswitching when communicating with people through observational note-taking, audiotaping, and videotaping. Cultural Identity itself is a rather abstract concept. How to scientifically quantify a person's cultural identity is inevitably controversial. This study focused on the questionnaires and observation of Malaysian Chinese undergraduate students' codeswitching behavior to project their attitudes towards their identity. Whether there are more scientific analysis methods still needs to be further discussed. On the other hand, the socio-economic status related to bilingual language behaviors could also be studied in

further study, especially in teacher education. It could be studied as it applies to teachers' beliefs, attitudes, and academic expectations of bilingual students.

\section{Acknowledgements}

This research is supported by the project from Language and Culture Research Institute (2019WGYYWH01). 


\section{Conflicts of Interest}

The author declares no conflicts of interest regarding the publication of this paper.

\section{References}

Berthold, M., Mangubhai, F., \& Batorowicz, K. (1997). Bilingualism and Multiculturalism: Study Book. Toowoomba: Distance Education Centre, University of Southern Queensland.

Bucholtz, M., \& Hall, K. (2003). Sociolinguistic Nostalgia and the Authentication of Identity. Journal of Sociolinguistics, 7, 398-416. https://doi.org/10.1111/1467-9481.00232

Bucholtz, M., \& Hall, K. (2004a). Language and Identity. In A. Duranti (Ed.), A Companion to Linguistic Anthropology (pp. 369-394). Malden, MA: Blackwell. https://doi.org/10.1002/9780470996522.ch16

Bucholtz, M., \& Hall, K. (2004b). Theorizing Identity in Language and Sexuality Research. Language in Society, 33, 501-547. https://doi.org/10.1017/S0047404504334020

Cameron, L. (2001). Teaching Languages to Young Learners. Cambridge: Cambridge University Press. https://doi.org/10.1017/CBO9780511733109

Commins, J. (1989). A Theoretical Framework for Bilingual Special Education. Exceptional Children, 56, 111-119.

Crystal, D. (1987). The Cambridge Encyclopedia of Language. Cambridge: Cambridge University Press.

David, M. K. (2001). The Sindhis of Malaysia. London: ASEAN Academic Press.

David, M. K. (2003). Functions of Code-Switching in Malaysian Courtrooms. Multilingua, 21, 1-24. https://doi.org/10.1515/mult.2003.005

David, M. K. (2006). Language Choices and Discourse of Malaysian Families: Case Studies of Families in Kuala Lumpur, Malaysia. Petaling Jaya: SIRD.

David, M. K. (2009). Politeness in Intergenerational Malaysian Sindhi Discourse: An Accommodation Perspective. In M. K. David (Ed.), Politeness in Malaysian Family Talk (pp. 78-97). Kuala Lumpur, Petaling Jaya: SIRD.

Dumanig, F. (2010). Language Choice in Interracial Marriages: The Case of Filipino Malaysian Couples. Dissertation.com.

Fishman, D. B. (1999). The Case for Pragmatic Psychology. New York: University Press.

Gee, J. P. (2005). An Introduction to Discourse Analysis: Theory and Method. London: Routledge.

Gumperz, J. (1982). Discourse Strategies. Cambridge: Cambridge University Press. https://doi.org/10.1017/CBO9780511611834

Hamers, J. F., \& Blanc, M. H. A. (2000). Bilingualism and Bilingualism. Cambridge: Cambridge University Press. https://doi.org/10.1017/CBO9780511605796

Hong, L. F. (2007). The Phenomenon of Language Mosaic of Chinese Malaysians-The Expression of Language Fusion. Southeast Asian Studies, 4, 71-76.

Hong, L. F. (2010). On the Phenomenon of the Transfer of the Mother Tongue of the Chinese in Malaysia. Chinese and Overseas Chinese History Studies, 4, 32-41.

Jamaliah, M. J. (1995). The Pragmatics of Cross-Cultural Communication in a Malaysian Context. In Z. A. Majid, \& L. M. Baskaran (Eds.), Rules of Speaking: Verbal Interactions at Play (pp. 112-124). Petaling Jaya: Pelanduk Publications.

Jariah, M. J. (2003). Code-Switching for Power-Wielding: Inter-Gender Discourse at the 
Workplace. Multilingual, 22, 41-57. https://doi.org/10.1515/mult.2003.003

Jariah, M. J. (2006). On Learning to be Assertive: Women and Public. Discourse, 5, 43-58. https://doi.org/10.1515/MULTI.2006.004

Kow, Y. C. (2003). Code-Switching for a Purpose: Focus on Malaysian Pre-School Children. Multilingual, 22, 59-77. https://doi.org/10.1515/mult.2003.004

Kuang, C. H. (2002). The Implication of Lah, and Hah as Used by Some Malaysian Speakers. Journal Bahasa Modern, 13, 77-90.

Le Vasan, M. (1996). System and Process in Computer-Mediated Discourse: A Case Study of Business Communication in a Malaysian Corporation. Unpublished Ph.D. Dissertation, Kuala Lumpur: University of Malaya.

Lim, C. G. (1997). Successful Intercultural Negotiations: A Matter of Attitude. Journal of Language for International Business, 8, 19-31.

Mckinley, C. J., Mastro, D., \& Warber, K. M. (2014). Social Identity Theory as a Framework for Understanding the Effects of Exposure to Positive Media Images of Self and Others on Intergroup Outcomes. International Journal of Communication, 8 , 1049-1068.

Meyerhoff, M. (2006). Introducing Sociolinguistics. London: Routledge, Taylor \& Francis. https://doi.org/10.4324/9780203966709

Morais, J. (1991). Constraints on the Development of Phonemic Awareness. In S. A. Brady, \& D. P. Shankweiler (Eds.), Phonological Processes in Literacy (pp. 5-27). Hillsdale, NJ: Lawrence Erlbaum Associates Inc.

Myers-Scotton, C. (1993). Social Motivations for Code Switching. Evidence from Africa. Oxford: Clarendon Press.

Omar, A. H. (1993). Contact Languages in the Encyclopedia of Malaysia. In D. Millet (Ed.), Languages and Literature (pp. 9, 13-14). Singapore: Pte Ltd., 2004.

Paltridge, B. (2006). Discourse Analysis. In J. D. Brown, \& Christine (Eds.), The Cambridge Guide to Research in Language Teaching and Learning (pp. 134-139). Cambridge: Cambridge University Press.

Skiba, S. (1997). Code-Switching as a Countenance of Language Interference. The Internet TESL Journal.

Stets, J. E., \& Burke, P. J. (2000). Identity Theory and Social Identity Theory. Social Psychology Quarterly, 63, 224-237. https://doi.org/10.2307/2695870

Tabouret-Keller, A. (1997). Language and Identity. In F. Coulmas (Eds.), The Handbook of Sociolinguistics (315-326). Oxford: Blackwell Publishing Ltd. https://doi.org/10.1002/9781405166256.ch19

Tajfel, H., \& Turner, J. C. (1985). The Social Identity Theory of Intergroup Behavior. In S. Worchel, \& W. G. Austin (Eds.), Psychology of Intergroup Relations (2nd ed., pp. 7-24). Chicago, IL: Nelson-Hall.

Tan, A. K. (1993). Language Choice and Social Class in the Transaction Domain in Singapore. Unpublished Master's Thesis, Singapore: National University of Singapore.

Thornborrow, J. (1999). Language and Identity. In S. Thomas, \& S. Wareing (Eds.), Language, Society, and Power: An Introduction (pp. 135-149). London: Routledge.

Widyawati, M. (2015). Pengaruh Pelatihan Terhadap Prestasi Kerja Pegawai Pada Inspektorat Kabupaten Rokan Hulu. Jurnal Ekonomi dan Bisnis, 11, 1-13. https://doi.org/10.36805/bi.v1i1.1181 